\title{
Democracia disjuntiva e cidadania insurgente
}

(HOLSTON, James. Cidadania Insurgente: disjunções da democracia e da modernidade no Brasil. São Paulo: Companhia das Letras, 2013).

Marcus Cardoso*

A publicação do livro Cidadania insurgente: disjunções da democracia e da modernidade no Brasil (2013), de James Holston, não poderia ter ocorrido em momento mais oportuno. A partir de junho de 2013, protestos contra o aumento das tarifas de ônibus, contra o uso excessivo da força por parte de policiais e contra os gastos exorbitantes da Copa da Mundo mobilizaram multidões em São Paulo, Belo Horizonte, Porto Alegre, Brasília e Rio de Janeiro. Não bastasse isso, no mês de dezembro do mesmo ano irromperam das periferias em direção aos shop-pings preferidos das classes média e alta de São Paulo os chamados "rolezinhos"; encontros marcados via internet por jovens pobres com o objetivo de "zoar", categoria nativa que expressa a intenção de se divertir. A reação imediata dos administradores destes estabelecimentos e do seu público habitual foi a tentativa, muitas vezes bem sucedida, de impedir o acesso destes jovens, estigmatizando-os. O potencial analítico destes dois eventos é estimulante. De uma só tacada eles desnudam nossa formulação tradicional de cidadania e nos instigam a refletir sobre as transformações em curso nas últimas décadas.

O que torna o livro providencial neste momento de efervescência é sua discussão acerca da emergência de uma cidadania urbana que tem as grandes cidades como espaço e objeto de reivindicações, arenas onde irrompem manifestações que demandam acesso a direitos, denunciam injustiças e desestabilizam privilégios historicamente enraizados nos costumes e nas leis brasileiras. Ao costurar historiografia, análise sociológica e etnografia, Holston sustenta (capítulo 1) que o processo histórico desencadeado pelo adensamento populacional nas grandes capitais e a criação das periferias fomentou a insurgência de uma cidadania que tem como protagonista grupos socioeconomicamente vulneráveis, que até então viam a lei e o sistema de justiça como instrumentos, na mão de outros, para sua subjugação.

O livro começa com uma indagação que não é propriamente original: o que torna nossa cidadania singular? A resposta começa a ser esboçada pela comparação com

\footnotetext{
* Doutor em antropologia pela UnB. Atualmente realiza estágio pós-doutoral, com financiamento do CNPq, no PPGAS/ DAN/UnB, onde é pesquisador colaborador. $<$ marcusacardoso@ gmail.com>.
} 
as formulações da cidadania francesa e estadunidense, experiências que teriam em comum a presença de um "ideal radical de igualdade" (p. 95) - que toma a identificação de um indivíduo como membro pleno do Estado-Nação como medida que garante a igualdade de tratamento - dando sentido aos seus processos históricos de distribuição de direitos (capítulos 2 e 3). Não é o nosso caso. No Brasil opera uma cidadania diferenciada na qual a incorporação dos indivíduos ao Estado-Nação não implica na igualdade legal entre os cidadãos. Nossa formulação da cidadania toma o status atribuído a categorias sociais específicas como medida para o reconhecimento de direitos e a observância de diferenças sociais da ordem de gênero, raça, ocupação, propriedade, renda e educação, que são critérios utilizados para sua distribuição seletiva entre cidadãos de diferentes tipos. A cidadania, no nosso caso, não equipara cidadãos, antes disso, é uma medida "para diferenciar e uma forma de distanciar as pessoas umas das outras" (p. 23).

Infere-se da popularidade adquirida pela máxima atribuída à Rui Barbosa que o princípio de distribuição desigual dos direitos é acolhido positivamente por parte majoritária dos operadores do sistema de justiça, ideologicamente justificado como forma de compensar desigualdades sociais preexistentes. A questão, como diversos cientistas sociais brasileiros apontaram antes de Holston, é que, na prática, ao longo de nossa história, o sistema de distribuição diferenciada de direitos serviu mais como mecanismo para legitimar e perpetuar desigualdades do que para compensá-las.

[E] num sistema de direitos de cidadania assim baseado na imunidade de alguns e na incapacidade de outros, os direitos se tornam relações de privilégio que atuam sem a obrigatoriedade do dever para com aqueles que não têm o poder de impor suas reivindicações (p. 333).

Ainda na primeira parte do livro, Holston avança contra a interpretação dos dilemas da cidadania brasileira elaborada por Da Matta, resgatando os argumentos do antropólogo brasileiro no que concerne às demandas por tratamento especial na sociedade brasileira, para depois contestá-los. Segundo a formulação de Da Matta, no Brasil operam dois princípios organizadores da vida social que são complementares mas contraditórios. Por um lado há o universo das leis impessoais, da cidadania formal que ignora as complementariedades e gradações, que nivela todos à categoria de indivíduos portadores dos mesmos direitos e deveres fundamentais. Por outro, somos uma sociedade na qual as relações pessoais desempenham papel central na forma como concebemos e organizamos nosso mundo social. Nesta tensão, "pessoa" se sobrepõe a "indivíduo". Em um mundo social que valoriza mediações tradicionais, a cidadania é carregada de valor negativo; cidadão é aquele indivíduo que não tem relações pessoais significativas que Ihe propicie reivindicar uma aplicação personalizada da lei que o favoreça. 
Holston discorda que as demandas por tratamento especial no Brasil revelam uma oposição estrutural entre indivíduo e pessoa, onde a última é usada como medida para exigir uma aplicação singular da lei. Valendo-se da análise das Constituições brasileiras de diferentes períodos históricos, ele sustenta que nossa formulação da cidadania comporta um sistema de distribuição diferenciada de direitos justamente porque nela fundem-se indivíduo e pessoa, legalizando privilégios. Por isso,

nenhuma exigência especial é necessária. O indivíduo é o depositário de direitos que lhes são conferidos porque ele ou ela são um certo tipo de pessoa social (p. 45).

Holston também avança contra as interpretações de que no Brasil as leis sejam inoperantes. Ao contrário disso, ao longo da história, o seu uso pelas elites nacionais tem sido especialmente eficaz na manutenção de uma estrutura social profundamente hierarquizada que perpetua privilégios em prejuízo de grande parcela dos brasileiros. O que temos é o "mau governo da lei" (p. 44), instrumentalizada como

um sistema de estratagemas e complicações burocráticas usado pelo Estado e por indivíduos para ofuscar problemas, neutralizar oponentes, garantir a impunidade e, acima de tudo, legalizar o ilegal (p. 44).

A legislação fundiária (capítulo 4) é o exemplo por excelência do "mau governo da lei". As leis de terra no Brasil foram "um instrumento de desordem calculada" (p. 266), elaboradas para favorecer a manutenção de conflitos e incorporar ilegalidades dentro dos processos legais, beneficiando grupos com recursos políticos e econômicos capazes de fazer valer seus interesses. O resultado foi a concentração de terra na mão de poucos brasileiros.

O processo de urbanização no país, com o desenvolvimento das grandes cidades, repetiu o mesmo padrão de exclusão à propriedade que marcou o acesso à terra no campo, dificultando a posse legal de lotes nos centros urbanos. Holston é feliz ao demonstrar (capítulo 5) que os mesmo fatores que fragmentaram e subjugaram os pobres rurais - acesso restrito à terra e aos direitos políticos, ilegalidades na moradia, "mau governo da lei" - também recaíram sobre os trabalhadores urbanos, impedindo que tivessem a experiência substantiva da cidadania. O caso de São Paulo é tomado como exemplar. Após a intensa industrialização, sob o discurso da modernização, levou-se adiante o processo de segregação espacial com a expulsão dos trabalhadores pobres das zonas centrais da cidade. A solução encontrada foi a criação das periferias onde as levas de migrantes puderam assentar residência, construindo suas moradias ilegais.

A partir do quinto capítulo a discussão sobre cidadania insurgente ganha corpo. A consolidação das periferias, com tudo que envolveu este processo - ocupação ilegal 
de terras, conflitos em torno da sua posse, novas formas de organização política, construção e melhoramento das moradias - fez emergir novos atores políticos e uma nova concepção de cidadania que questiona regimes de privilégios. Esses novos sujeitos políticos nasceram da luta pela legalização das moradias e da experiência da propriedade, ressignificando práticas e "valores vinculados classicamente à propriedade fundiária na história da cidadania" (p. 228).

Neste percurso, a lei passou a ser um ativo para os moradores da periferia, que aprenderam a dominar as complicações da legislação a seu favor, tal como as elites sempre o fizeram. Mas, neste caso, destaca Holston, o "mau governo da lei" não expressaria uma tentativa de corromper a cidadania, mas sim de se incluir nela. A utilização dos signos diferenciados para sua contestação representaria uma ruptura com este modelo de cidadania com o intuito de demandar tratamento igualitário.

O caso etnográfico do Jardim das Camélias (capítulo 6) - bairro autoconstruído por trabalhadores pobres da cidade de São Paulo - é exemplar para o antropólogo. A luta pela moradia produziu entre seus moradores "um envolvimento sem precedentes com a lei que tornou seus líderes confiantes o suficiente para enfrentar oficiais de justiça com argumentos legais" (p. 304). Neste processo, uma certa linguagem dos direitos de cidadania, construída a partir da experiência urbana, tornou-se gramatical. Holston sustenta que diferente do modelo tradicional, fundamentado no princípio de incorporação do Estado-Nação, a cidadania insurgente expressa desejos e demandas por direitos à cidade (capítulo 7). No caso dos moradores do Jardim das Camélias, as décadas trabalhando em São Paulo fizeram surgir a percepção de que eram "contribuidores da cidade" (p. 27), parte fundamental do seu processo de construção e funcionamento. Por esta condição adquiriram direitos sobre a cidade. A legalização dos lotes configurava um destes direitos.

Fundamental para Holston é convencer-nos de que os movimentos vindos das periferias urbanas fizeram surgir na esfera pública novos atores políticos que, a partir da linguagem dos direitos, expandiram a cidadania democrática calcada em princí-

1. A expressão "democracia disjuntiva" serve para classificar democracias emergentes com um sistema eleitoral saudável, mas incapazes de fazer garantir os direitos civis, sociais e culturais de seus cidadãos de forma universal. pios igualitários, desestabilizando o regime diferenciado, sem substituí-lo, fenômeno que sinaliza a progressiva legitimação do "conceito insurgente de direitos gerais fundamentados na constituição ou em texto" (p. 329). Este movimento, que está em processo nas últimas décadas, tem o potencial de contestar os aspectos disjuntivos de nossa democracia ${ }^{1}$, criando condições para a consolidação de um modelo capaz de diminuir desigualdades e injustiças históricas.

Mas este processo de expansão não é estável e pode sofrer revezes. A cidadania insurgente provocou fortes reações contrárias por parte dos grupos sociais que historicamente se beneficiaram de um modelo de perpetuação das desigualdades 
sociais, que lançaram mão do entrincheiramento na tentativa de restabelecer o antigo regime de diferenciação (capítulo 8). Se as classes trabalhadoras adquiriram direitos à cidade e se as leis não garantem mais o tratamento diferenciado a partir do status, outros procedimentos foram adotados para expressar o ressentimento com a erosão do antigo pacto social. Enclaves residenciais e comerciais fortificados são criados com o intuito de segregar, espaços públicos são abandonados para se evitar o encontro indesejado, o brado contra os discurso dos direitos humanos ganha força, assim como o apelo ao recrudescimento da violência policial articulada à criminalização das classes trabalhadoras.

Holston encaminha sua conclusão argumentando que o entrincheiramento na tentativa de manter o antigo regime de ordem prejudica a distribuição de direitos. No seu confronto com os movimentos de contestação da desigualdade criam-se novas injustiças e incivilidades que têm o potencial de colocar em perigo o processo de expansão da cidadania democrática no Brasil, ameaçando os avanços conquistados até aqui. As fortes reações de resistência, contudo - como Holston procura demonstrar nas últimas páginas de seu livro -, não foram capazes, até este momento, de evitar a expansão da legitimidade da cidadania democrática insurgente. 